\title{
Fraction Bound
}

National Cancer Institute

\section{Source}

National Cancer Institute. Fraction Bound. NCI Thesaurus. Code C154840.

The ratio of bound drug concentration to the total concentration. 